\title{
Coefficient of Friction, Angle of Repose, Specific Gravity, and Bulk Density of Coffee Fruits and Coffee Beans ${ }^{1}$
}

\author{
Adolfo Eschenwald and Carl W. Hall ${ }^{2}$
}

INTRODUCTION

Coffee is a very important crop in the world market. On its production, processing and marketing depends, to a great extent, the economy of several countries in North America, South America, Africa, and Asia. Over 90 percent of American families serve coffee and more American families use coffee regularly than any other table item except sugar and salt. A great amount of research work has been done on varieties and cultural practices, but very little basic information is available on handling and processing.

Coffee requires considerable farm handling during processing, from the time the ripe fruits are picked until the product is marketed. Basic information on the physical properties of the coffee fruit and coffee beans is an essential engineering tool for the design of processing systems and structures (fig. 1). The study reported herein was carried out to obtain information on some of the physical properties of coffee.

The specific objectives of this study were:

1. To determine the coefficient of friction between the coffee fruits, beans, and pulp at different stages of the process of elaboration and the important materials of construction.

2. To determine the average specific gravity and bulk density of coffee fruits and pulp, and their applicability to sorting and conveying.

\section{REVIEW OF LITERATURE}

The coefficient of friction of a product against a certain surface is expressed as the tangent of the minimum angle at which the product slides over the surface. The angle of repose is the minimum angle at which the product slides over itself. Wifred $(8)^{3}$ reported some results of studies on angle of repose and coefficient of friction for wheat, barley, oats, corn, beans, peas, and flaxseed on rough boards, iron, and concrete. Jamieson (2) de-

1 Based on "Some basic properties of the coffee fruit and coffee beans," thesis of Adolfo Eschenwald, for M.S. degree, Department of Agricultural Engineering, Michigan State University, East Lansing, Mich., 1959.

2 Head, Department of Agricultural Engineering, Puerto Rico Agricultural Experiment Station, Mayagüez, P.R., (formerly a graduate student at Michigan State University) and Professor, Agricultural Engineering, Michigan State University.

${ }^{3}$ Italic numbers in parentheses refer to Literature Cited, p. 25. 
termined the coefficient of friction between wheat and various materials of construction. Ketchum (4) reported data compiled from experiments conducted by V. Pleisener on the coefficient of friction for wheat and rye and bin-wall materials. Values reported for similar materials and grain are different from the values reported by Jamieson (2) probably due to variety and moisture content. Kramer $(5)$ determined the angle of repose and coefficient of friction for rice and several construction materials. The moisture content of the product was considered. Hintz and Schinke (1) determined the coefficient of sliding friction for chopped corn and alfalfa on steel at sliding velocities from 0 to 6,000 f.p.m. Richter (7) conducted laboratory tests to determine the friction coefficient for chopped hay, straw, and silage on galvanized steel. The information is used as a basis for the

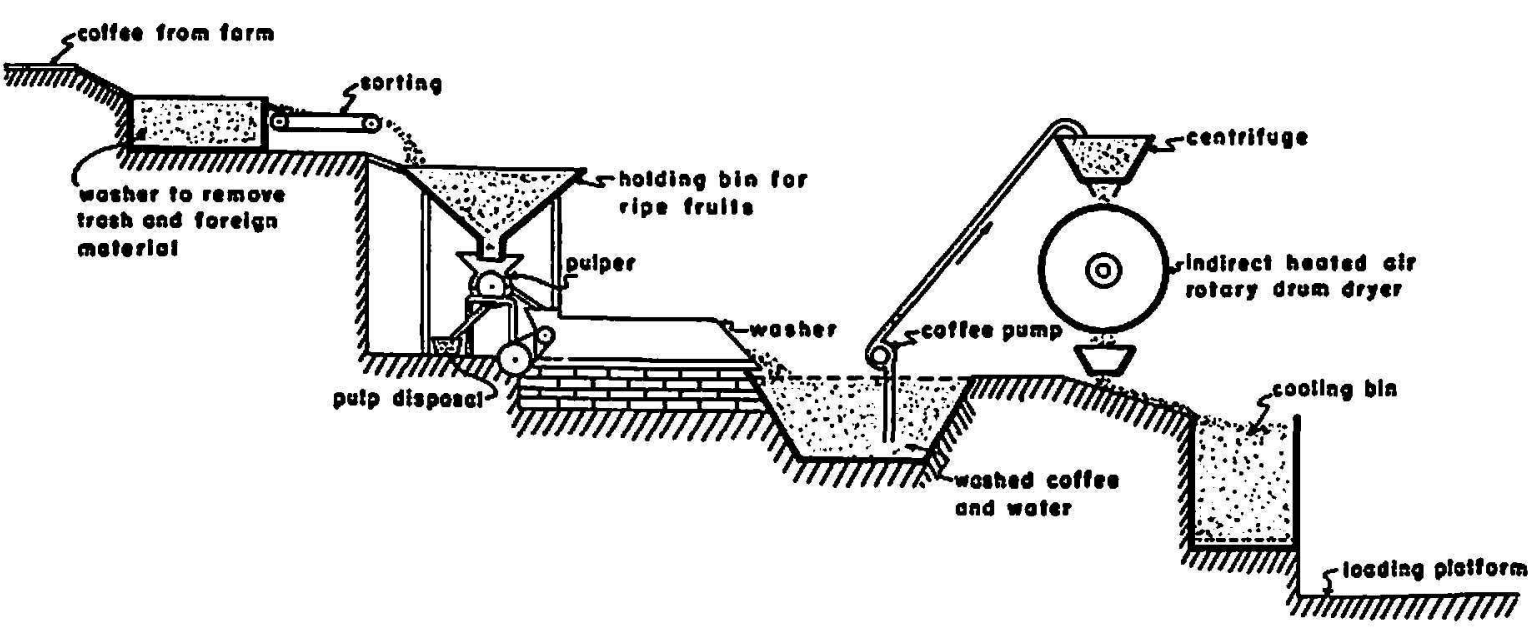

Fig. 1.-A coffee-processing flow-chart.

design of conveyors, bins, and gravity-flow systems. Kinch (3) reported data on the coefficient of sliding friction for passion-fruit slices while explaining the design of a passion-fruit centrifuge.

Measurements of the specific gravity and bulk density of a crop are also of value. The specific gravity of a product is expressed as the ratio of mass of the body to the mass of an equal volume of water at $4^{\circ} \mathrm{C}$. Work on specific gravity and air space in grain and seed was performed by the use of the specific-gravity-bottle principle. Mercury was used as a fluid. Pflug, et al., (6) designed, constructed, and operated, at Michigan State University, a specific-gravity separator for potatoes. Sodium chloride brine was used as the separating medium.

\section{EXPERIMENTAL PROCEDURE}

The coffee used in this study was Coffea arabica "forma nativa," from Puerto Rico. A conventional tilting table, shown in figure 2, was used to determine the angle at which the product slid over the surface. A card- 
board, bottomless frame was used to hold the sample, so that the product did not roll or tip and in such a way that only the product came in contact with the surface being tested. The table was slowly tilted until the product slid on the surface. The angle was measured with a protractor, the tangent being considered as the coefficient of friction. All tests where the product tilted or rolled were discarded. The data in table 1 are the average of four tests where the product slid over the surface without rolling and the holding frame did not come in contact with the surface.

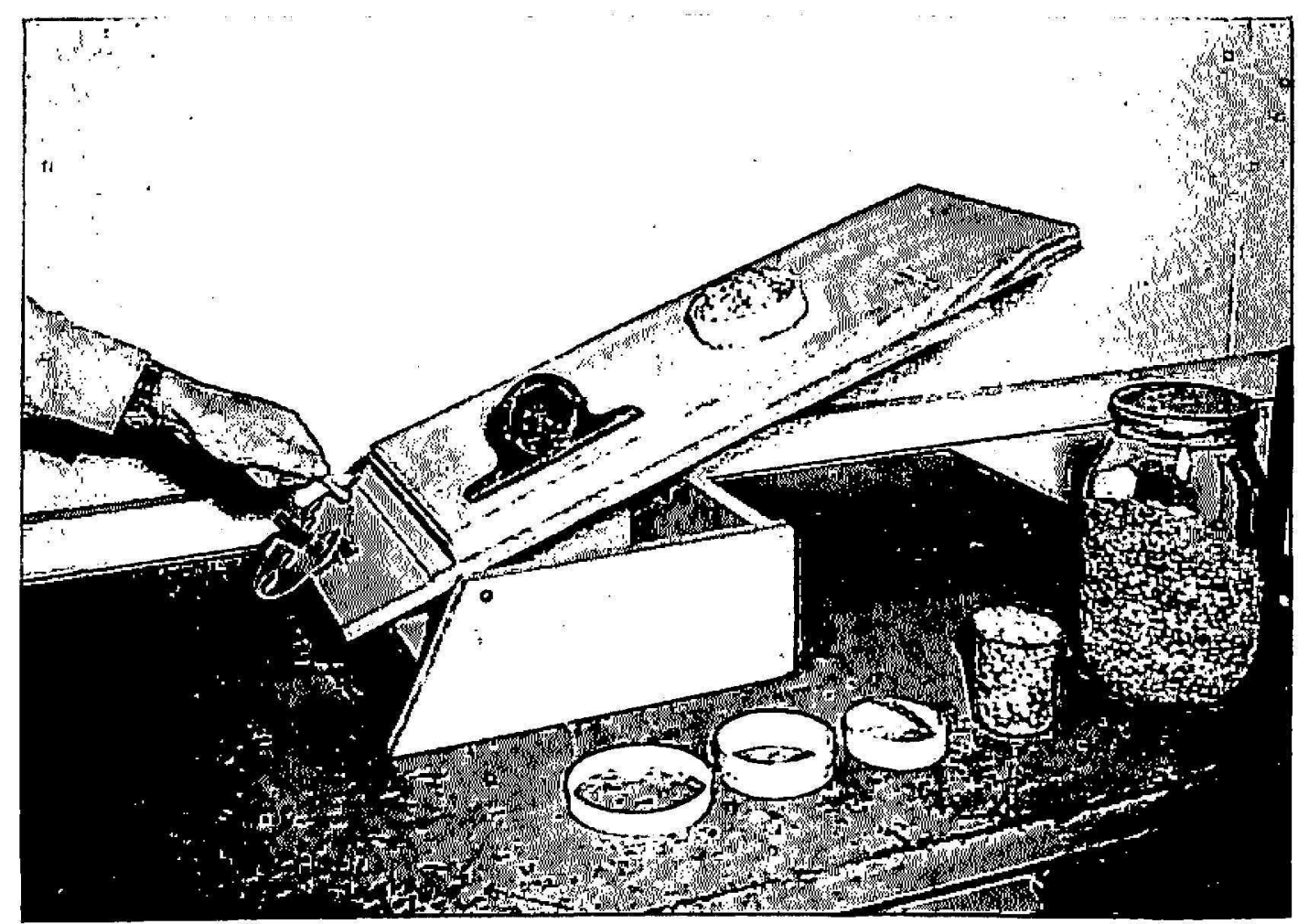

FIG. 2.-Tilting table used for determinations of the coefficient of friction.

The angle of repose of the product, or the coefficient of friction of the fruit over itself, was determined as follows: $A$ box 12 inches wide, 12 inches long, and 6 inches high with a round orifice, and 2 inches in diameter in the center of the bottom, was prepared. A sliding gate on the underside of the orifice permitted the opening to be closed or opened without disturbing the box contents. The box was leveled on top of two blocks providing a free flow. The product was placed in the box and the gate opened, it flowed out undisturbed, until its normal angle of repose was reached. This angle was measured and its tangent was considered the coefficient of friction of the product over itself. Data obtained are also included in table 1.

The specific gravity was determined from a random sample of 100 green and 100 ripe fruits. A Boerner sampler was used to assure the selection of representative fruits. Distilled water at known temperatures was used 
TABLE 1.-Coefficient of friction of coffee fruits and coffee beans measured on various materials of construction

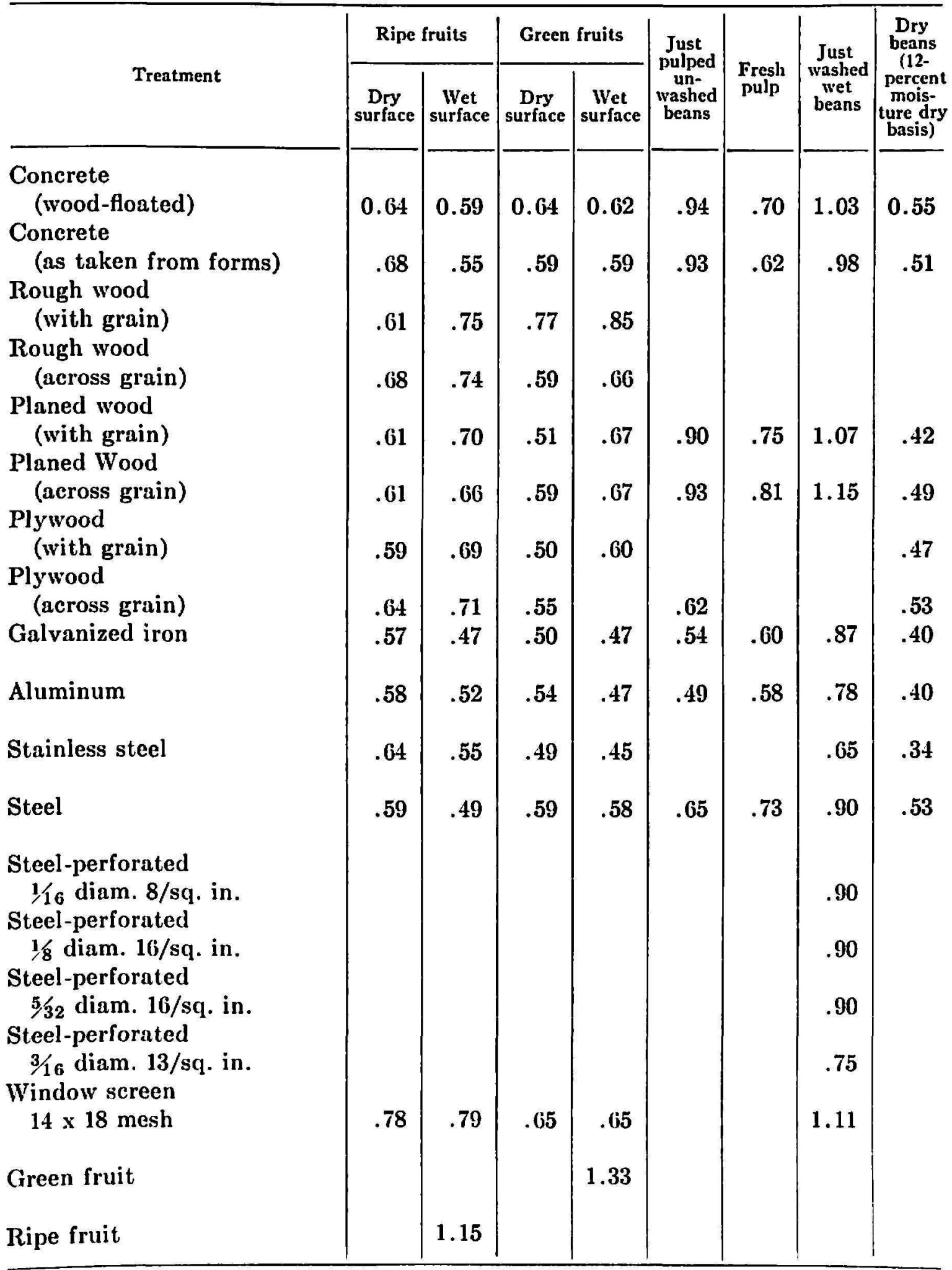

for the determinations by the conventional Archimides' principle. An analytical balance was used for weighing to an accuracy of 4 decimal places. The fresh coffee fruits do not absorb water because of their almost impervious covering and the fact that the intracellular space is saturated, so there is 
no water-vapor pressure gradient at uniform temperature and under saturation conditions. The fruits that floated were discarded, since upon opening they exhibited aborted embryos. The bulk densities for green and ripe fruits and the pulp were obtained by weighing a certain quantity of the product and then measuring the volume this same amount occupied when in the normal state.

\section{RESULTS AND DISCUSSION}

The results obtained for the coefficient of friction between the product and different materials of construction are presented in table 1. Higher

TABLE 2.-Specific gravily and densily of green and ripe coffee fruits

\begin{tabular}{|c|c|c|c|c|}
\hline Condition of fruits & Specific gravity' & $\begin{array}{l}\text { Temperature of } \\
\text { water, }{ }^{\circ} \mathrm{F},{ }^{1}\end{array}$ & \multicolumn{2}{|c|}{ Weight density in -1} \\
\hline $\begin{array}{l}\text { Green } \\
\text { Ripe }\end{array}$ & $\begin{array}{l}1.0722^{*} \\
1.0454^{* *}\end{array}$ & $\begin{array}{l}79^{\circ} \mathrm{F} . \\
80^{\circ} \mathrm{F} .\end{array}$ & $\begin{array}{c}\text { Gm./ct. cm. } \\
1.0687 \\
1.0415\end{array}$ & $\begin{array}{c}L b . / c u . f t . \\
66.76 \\
65.07\end{array}$ \\
\hline
\end{tabular}

${ }^{1}$ Average of 100 determinations. * Ranges from 1.0063 to 1.1163 ; ${ }^{* *}$ ranges from 1.0072 to 1.0884 .

TABLE 3.-Bulk densily of coffee fruits and coffee pulp

\begin{tabular}{l|c|c|c|c|c}
\hline \multirow{2}{*}{ Fruits or pulp } & \multicolumn{2}{|c|}{ Number of fruits' per- } & \multicolumn{2}{|c|}{ Weight density as-1 } & Void space \\
\cline { 2 - 5 } & Cubic centimeter & Cubic foot & Gm./cu. cm. & Lb./cu. ft. & \\
\hline (percent) \\
\hline Green & 0.546 & 15,460 & 0.601 & 37.54 & 44 \\
Ripe & .361 & 10,222 & .596 & 37.24 & 43 \\
Pulp & & & .248 & 15.48 & \\
\hline
\end{tabular}

1 Average of 20 determinations.

2 Freshly removed pulp.

values were obtained for the wet product on wood. These results are to be expected because the grain of the wood becomes rougher upon soaking with water. Coefficients of friction for perforated material are useful for studying the movement of material from which excess water is removed after washing and before drying.

No significant difference was found in the average specific gravity and density of green and ripe fruits. (See tables 2 and 3.) The specific gravity for the green fruits varied from 1.0063 to 1.1163 and for the ripe fruits from 1.0072 to 1.0884 . Contrary to expectations the green fruits showed a higher average specific gravity than the ripe. The higher average value in specific gravity and density of the green fruit seems to have been caused by some physicochemical changes that occur on ripening. The values obtained for 
specific gravity, bulk density, and void space for coffee may be compared with the values obtained for wheat, oats, corn, buckwheat, and millet by Zink (9). Results obtained are summarized in tables 2 and 3.

\section{SUMMARY}

The coefficients of friction between coffee fruit, coffee beans, and different construction materials were determined by the tilting-table method. Determinations were performed for dry-surface and wet-surface fruit, pulp, pulped unwashed-wet, and pulped washed-dry beans. The pulped, washed, wet beans showed the highest coefficient of friction when compared with fruits, pulp, pulped-unwashed or pulped-washed dry beans for all materials of construction. Values obtained ranged from 0.65 for stainless steel to 1.15 for planed wood (across grain). The dry beans, 12-percent moisture content, dry basis, showed the lowest coefficient of friction when compared with fruits, pulp, pulped-unwashed or pulped-washed wet beans. The values obtained varied from 0.34 for stainless steel to 0.55 for concrete. These values are similar to those obtained for rough rice by Kramer (5) on the same materials.

The specific gravity for green fruit varied from 1.0063 to 1.1163 and for the ripe fruit from 1.0072 to 1.0884 . The values obtained for specific gravity, bulk density, and void space for coffee are similar to the values published by Zink (9) for wheat, oats, buckwheat, and millet.

\section{RESUMEN}

El coeficiente de rozamiento entre el café en fruta, el café despulpado y distintos materiales de construcción se determinó mediante el método convencional del plano inclinado. Se hicieron determinaciones entre café en fruta, café despulpado húmedo y café despulpado seco sin pilar con distintos materiales corrientes de construcción, a base de superficies secas y húmedas. El café recién despulpado y mojado mostró el mayor coeficiente de rozamiento. Los valores obtenidos fluctuaron desde 0.65 para acero inoxidable hasta 1.15 para madera acepillada. El café pergamino con 12 por ciento de humedad (base seca) demostró el más bajo coeficiente de rozamiento y los valores obtenidos variaron desde 0.34 para acero inoxidable hasta 0.55 para hormigón. Estos valores se asemejan mucho a los valores obtenidos por Kramer (5) para el arroz en cáscara.

El peso específico obtenido para la fruta de café verde varió desde 1.0063 hasta 1.1163 y para la fruta madura desde 1.0072 hasta 1.0884 .

Los valores obtenidos para peso específico, densidad de volumen y espacio libre entre el producto, es similar al publicado por Zink (9) para trigo, avena y millo. 


\section{LITERATURE CITED}

1. Hintz, O. E. and Schinke, R., Coefficient of Sliding Friction for Corn and Alfalfa on Steel, Advanced Engineering Department, International Harvester Co., Report 3-A1866-52, R.I. Chicago, Ill., 1952.

2. Jamieson, J. S., Grain pressures in deep bins, Can. Soc. Civ. Engs., Trans. 1093-17, 554-607, 1905.

3. Kinch, D. M., Development of the passion fruit centrifuge, paper presented at the annual meeting of the A.S.A.E. at Santa Barbara, Calif., June, 1958.

4. Ketchum, M. S. Design of Walls, Bins, and Grain Elevators, pp. 346-50, New York, N. Y., 1911.

5. Kramer, H. A., Factors influencing the design of bulk storage bins for rough rice, Agr. Eng. 25 463-6, 1944.

6. Pflug, I. J., Brandt, M. W., and Isleib, D. R., Specific gravity potato separator, Mich. Agri. Exp. Sla. Quart. Bul. 38 29-34, 1955.

7. Richter, D. W., Friction coefficients of some agricultural materials, Agr. Eng. $35411-3,1954$.

8. Wifred, A., The pressure of grain, Inst. Civ. Engs., Minutes of Proceedings, 121 $347-58,1898$.

9. Zink, F. J., Specific gravity and air space of grains and seeds, Agr. Eng. 16 439-40, 1935. 